\title{
Solicitações profissionais e sociais de professores de cursos de enfermagem no Brasil
}

Paulo Gomes Lima ${ }^{1}$

Patrícia Leal de Freitas Santos ${ }^{2}$

LIMA, P.G.; SANTOS, P.L.F. Professional and social requests of the nursing professor in Brazil. Interface - Comunic., Saude, Educ., v.15, n.39, p.1097-109, out./dez. 2011.

In this work we analyze the professional and social requests of the nursing professor in Brazil in view of the requirements, identity and didactichistorical training of their knowledge field through a literature review. The findings pointed to a necessary reflection in the area, breaking the purely instrumental logic both of the teacher and of the professional to be trained, as the actionreflection-action sieve gradually occupies the centrality of the interaction between knowledge and action in a humanized perspective.

Keywords: Nursing. Faculty nursing. Didactic-pedagogical training.
Neste trabalho analisamos as solicitações profissionais e sociais do professor universitário de cursos de enfermagem no Brasil frente às exigências históricometodológicas da enfermagem e dos profissionais que exercem a docência nessa área, por meio de uma revisão de literatura especializada. As conclusões apontam para uma necessária reflexão da área, rompendo com a lógica meramente instrumental, tanto do professor quanto do profissional a ser formado, à medida que o processo de ação-reflexão-ação ocupa a centralidade da interação dos saberes e fazeres, em uma perspectiva humanizadora.

Palavras-chave: Enfermagem. Docentes de enfermagem. Formação didáticopedagógica.
${ }^{1}$ Programa de PósGraduação Strictu Sensu, Universidade Federal da Grande Dourados (UFGD). Rua Barão do Rio Branco, 570, apto 203. Jd. Clímax, Dourados, MS, Brasil. 79.820-011. paulolima@ufgd.edu.br 


\section{Introdução}

No final do século XIX, um processo de urbanização lento e progressivo já se fazia sentir nas cidades que possuíam áreas de mercado mais intensas, como São Paulo e Rio de Janeiro. Esse processo acompanhava algumas mudanças político-econômicas no Brasil, como, por exemplo, a passagem da fase agroexportadora para a incipiente fase urbano-industrial, que teria mais ênfase na década de 1930, quando as cidades começavam a receber um contingente significativo de pessoas por conta do arranjo industrial inaugurado na recém república brasileira. As escolas de enfermagem surgem, portanto, ainda no final do século XIX, para dar conta de um contingente populacional crescente nas cidades frente aos desafios sociais e de mercado, cuja regularização da profissão do enfermeiro deu-se no século XX, corporificando status específico e solicitações de formação educacional para o seu exercício, cada vez mais sistematizadas.

Geovanini et al. (2002) acentuam que, no início da história da enfermagem, a preocupação era a formação de profissionais para dar assistência a doentes e feridos a partir de uma perspectiva instrumental e curativa. Nesse âmbito, a dimensão causa-efeito, comumente associada ao positivismo, ocupava a centralidade nas escolas de formação de enfermeiros, o que influenciaria significativamente a história da enfermagem liderada pela tradição de ensino dos países desenvolvidos, cujos modelos os demais países acabariam por assimilar.

Em relação à formação docente para o exercício do magistério no curso de enfermagem no Brasil, muitos profissionais buscavam noutros países (especialmente Estados Unidos e França) o seu referencial praxiológico, o que lhes conferia status e reconhecimento a ponto de ocuparem cargos de direção de escolas de enfermagem que, até então, ficavam sob a responsabilidade de enfermeiras americanas e francesas. A orientação pedagógica recebida pelos professores brasileiros de enfermagem centrava-se na dimensão pragmática causa-efeito transversalizando o século XX e chegando aos dias atuais (Pinhel, 2006). Essa última afirmação solicita, de forma recorrente, algumas indagações, como seguem.

Ao longo do tempo, temos ou não desenvolvido, no Brasil, a formação de professores para o Ensino Superior de enfermagem com uma perspectiva não meramente reducionista e utilitarista? Os acadêmicos da área desenvolvem uma perspectiva de ressignificar a enfermagem para além do cunho assistencialista, isto é, num processo de formação continuada em que o ensino, a pesquisa e a extensão estejam sempre evidenciadas?

Considerando essas questões e a partir da trajetória e desenvolvimento da enfermagem em nível Superior, o objetivo deste trabalho é problematizar a formação didático-pedagógica de professores nessa área e as recorrências significativas de sua intervenção numa perspectiva mais ampla, isto é, para além do caráter instrumental da profissão.

Organizamos este trabalho em quatro momentos interligados. O primeiro listando as exigências histórico-metodológicas da enfermagem e dos profissionais que exercem a docência nessa área; o segundo, um breve histórico do curso Superior de enfermagem no Brasil. O terceiro, a problematização da identidade profissional do professor de Ensino Superior nos cursos de enfermagem e, finalmente, as solicitações da formação didático-pedagógica requeridas desse profissional, considerando o comprometimento com a sua ação interventiva e respectiva ampliação da perspectiva profissional.

\section{Enfermagem e docência universitária: exigências histórico-metodológicas}

O desvelamento de um objeto histórico se dá pela disposição do professor (pesquisador) sobre o objeto pesquisado, ou seja, pelo desenvolvimento de sua ação- que é a primeira leitura da realidade contextual, de como se apresenta e de como se articulam todos os elementos e situações a ela pertinentes, situando um panorama da instituição, evento, curso, formação profissional, dentre outros (Lima, 2007). A ação leitora sobre a realidade permitirá o acesso ao diagnóstico da realidade, solicitando, ao pesquisador, uma reflexão intencional sobre as problemáticas identificadas e de como manter, aperfeiçoar ou transformar o que já é proveitoso para todos os atores.

A reflexão sobre a ação possibilitará a sugestão do coletivo frente às questões que se colocam no cotidiano, mas também, em nível individual, servirá ao professor como ponto de autoavaliação 
permanente quanto à validade e aproveitamento do que está desenvolvendo e como aprimorar ou mudar de direção pedagógica, se for o caso. O terceiro momento dialético e concomitante do processo será o retorno à própria prática ou ação, evidenciando uma ação transformada e disposta ao processo de transformação dos fazeres e amadurecimento do investigador ou do educador, em se tratando de sua prática didático-pedagógica. Não se pode destacar, nesse sentido, esse ou aquele elemento como o mais relevante do contexto desvelado, mas, no conjunto, procurar entendê-lo sob o eixo central da ação-reflexão-ação. Esta é nossa proposta a seguir.

Um episódio relevante no contexto histórico da sistematização da enfermagem, tanto na Inglaterra, com Florence Nightingale, quanto no Brasil, com Anna Nery, está ligado ao papel do voluntarismo exercido em períodos de guerras, imprimindo os valores militares como o valor de espírito de serviço (Rodrigues, 2000). A exigência histórica, explicitada no Brasil entre o final do século XIX e início do século XX, que se delineava quanto à formação do enfermeiro, além de se assentar numa base epistemológica meramente instrumental, recorria, paralelamente, ao sentimento ideológico salvacionista da profissão, qualificando-a como objeto de ação missionária. Esse processo era interiorizado tanto pelo professor de Ensino Superior que formava o enfermeiro, quanto pelo próprio profissional formado ou em formação, que materializava tal ideário em sua força de trabalho. Afora esse quadro, a inclinação para a profissão em nível de gênero fora circunscrita ao gênero feminino, isto é, somente nas mulheres as características humanizadoras e voluntaristas seriam reunidas, a ponto de doarem-se para o exercício da profissão, a exemplo do que fazia uma mãe.

Pires (2007) afirma que esta disposição social da profissão era conveniente: âmbito religioso e dimensão de gênero, simplificando, inclusive, o trabalho da docência para esta área, uma vez que o caráter instrumental e utilitarista já havia sido incorporado pelos candidatos à enfermagem.

Historicamente, a disciplinaridade orientou a formação profissional do enfermeiro em áreas específicas de atendimento preventivo e curativo. Tal orientação deveu-se ao tratamento científico válido e aceito pela ciência, destacadamente a partir do século XIX, quando da inauguração do positivismo. Assim, as contribuições objetivas das ciências naturais passariam a ser o vetor da epistemologia do campo científico como um todo, colocando à margem quaisquer outras possibilidades de desenvolvimento e tratamento dos objetos.

Isso se deveu, inclusive, à secundarização das ciências humanas na estrutura curricular de formação do enfermeiro - o que ainda continua nos dias atuais - relegada a espaços espremidos no início ou final da estrutura curricular, dentre os conteúdos considerados "nobres" ou centrais da enfermagem, reduzindo, ao mínimo necessário, a sua carga horária, e o pior, muitas vezes sem a necessária articulação com a totalidade do curso (Oguisso, Freitas, 2007).

É indispensável que os enfermeiros se apropriem de conhecimentos de outras disciplinas, dentre elas a História, a Filosofia, a Sociologia, refletindo um mundo que não se apresenta sem intencionalidades na exploração do trabalho e formação histórica de mentes e mão de obra que garantam o seu funcionamento pertinente. A ação-reflexão-ação sobre sua condição profissional, social e cidadã é dimensão imprescindível para a formação integral do profissional, quer seja do professor de Ensino Superior que escolheu a enfermagem como área de atuação ou do candidato a enfermeiro ou enfermeira que, ressignificando sua prática, a exercerá numa dimensão mais ampla do conhecimento, não reduzida ao fazer utilitarista, mas como uma das interfaces da produção do conhecimento em articulação com outras áreas.

A exigência histórica de mercado para a qualificação profissional, a partir da formação inicial, simplesmente continua com o mesmo projeto tradicional de reproduzir competências e habilidades necessárias ao atendimento do desenvolvimento ideológico do capital. É necessário observarmos que, quando o professor de Ensino Superior, particularmente da área de enfermagem, não se dá conta dessa lógica, não tomará posse de leituras distintas das solicitações sociais da própria profissão e nem sequer de seu papel de agente transformador na perspectiva de outra exigência histórica - a da concretude social, que deve primar pelo desenvolvimento do profissional em sua totalidade, considerando as distintas possibilidades e campo de imersão do enfermeiro não dissociado do quadro macrossocial que envolvem questões econômicas, culturais e orientadas por condicionantes sócio-históricos. 


\section{Curso de Enfermagem em nível Superior no Brasil}

Segundo Lima (2008), a exigência histórico-emancipadora do Ensino Superior no Brasil não deve prescindir da problematização acerca da docência no espaço universitário, e sua respectiva formação continuada deve se constituir objeto de constante atualização e recorrência, reivindicando a coerência propriamente científica da universidade como local privilegiado do conhecimento e da consistência entre o arcabouço discursivo e respectivas intervenções nas práticas pedagógicas.

As diretrizes da docência universitária no Brasil reiteram essa necessidade por meio das finalidades da Educação Superior, como se segue na Lei de Diretrizes e Bases da Educação Nacional n. 9.394/96 (Brasil, 1996), no Capítulo V - da Educação Superior:

Art. 43 - A Educação Superior tem por finalidade:

I - estimular a criação cultural e o desenvolvimento do espírito científico e do pensamento reflexivo;

II - formar diplomados nas diferentes áreas de conhecimento, aptos para a inserção em setores profissionais e para a participação no desenvolvimento da sociedade brasileira, e colaborar na sua formação contínua;

III - incentivar o trabalho de pesquisa e investigação científica, visando ao desenvolvimento da ciência e da tecnologia e da criação e difusão da cultura, e, desse modo, desenvolver o entendimento do homem e do meio em que vive;

IV - promover a divulgação de conhecimentos culturais, científicos e técnicos que constituem patrimônio da humanidade e comunicar o saber através do ensino, de publicações ou de outras formas de comunicação;

$\mathrm{V}$-suscitar o desejo permanente de aperfeiçoamento cultural e profissional e possibilitar a correspondente concretização, integrando os conhecimentos que vão sendo adquiridos numa estrutura intelectual sistematizadora do conhecimento de cada geração;

$\mathrm{VI}$ - estimular o conhecimento dos problemas do mundo presente, em particular os nacionais e regionais, prestar serviços especializados à comunidade e estabelecer com esta uma relação de reciprocidade;

VII - promover a extensão, aberta à participação da população, visando à difusão das conquistas e benefícios resultantes da criação cultural e da pesquisa científica e tecnológica geradas na instituição.

Depois de mais de uma década da promulgação desta lei, ainda procuramos romper politicamente com os modelos e ideologias subjacentes também nos cursos superiores. No âmbito da docência universitária na enfermagem e como um todo, o reposicionamento sociopolítico dessa solicitação não se dá de forma abrangente, visto que os paradigmas hegemônicos historicamente situados sobre a concepção de cientificidade (validação das ciências naturais como expressão do valor científico centrado na precisão, mensurabilidade, neutralidade, dentre outros) exercem expressões significativas sobre os fazeres docentes (Lima, 2008), inviabilizando um olhar mais plural sobre a missão e função da docência no Ensino Superior e das possibilidades de sua transformação. Goergen (1997, p.28) nos diz que, na medida em que a nossa sociedade está se tornando a sociedade do conhecimento, faz-se urgente " [...] reinventar uma ética social e coletiva que zele pela educação da razão em sentido mais abrangente, que não inclui apenas o teórico (a ciência), mas também o prático (as relações dos homens entre si e com a natureza)", mesmo em face da polêmica de que o sentido da razão foi perdido ao longo da modernidade.

Certamente, esse olhar traz elementos pontuais para a atualidade da discussão sobre as pistas necessárias que o professor do curso de enfermagem deve levar em consideração no desenvolvimento de seu trabalho na universidade. A tomada de consciência do processo de formação unidirecional do curso pode ser percebida pelos aspectos históricos no Brasil, apresentados a seguir, e que servem como pano de fundo para encaminhamentos necessários quanto ao papel do professor universitário no curso de enfermagem.

No final do século XIX (1889), inaugurada a república no Brasil, imediatamente foram evidenciados problemas em distintas áreas infraestruturais, inclusive na saúde. Um das mais emergentes era a falta de pessoal qualificado para o atendimento à população, exigência esta demandada pelo crescente interesse hegemônico que apostava no crescimento industrial, ainda em projeto no Brasil. Assim, por meio do 
Decreto 791/1890 (Brasil, 2010), para dar conta das solicitações do Hospício Nacional de Alienados ou Hospício Dom Pedro II, foi criada a Escola de Enfermeiros e Enfermeiras, que seria denominada de Escola Alfredo Pinto, e que tinha como referencial formativo o modelo francês (ensino profissional uniforme coordenado por grupo específico da área de conhecimento).

Terminada a primeira guerra mundial, foi criado o Departamento Nacional de Saúde Pública, por meio do Decreto 3.987 de 02/01/1920 (Brasil, 1921), iniciando, assim, o serviço de visitadoras, que tinha por objetivo atender aos enfermos em suas casas, visando à prevenção mais do que a cura da doença (Paixão, 1969). Até então não existia uma escola de enfermagem propriamente dita, reconhecida oficialmente, o que viria acontecer somente com a criação do citado Departamento. Vale destacar que os interesses do mundo capitalista estavam disseminados em inúmeras fundações e organismos multilaterais de apoio técnico e financiamento, garantindo ideologicamente sua hegemonia. Não distante desta realidade, por meio do apoio de uma instituição norte-americana, a Fundação Rockfeller, foi fundada oficialmente a EEDNSP (Escola de Enfermagem do Departamento Nacional de Saúde), criada pelo Decreto 15.799 de 10/11/1922 (Brasil, 1923), entrando em funcionamento em 19/ 03/1923, cuja orientação da formação profissional assentava-se na enfermagem nightingaleana. A educação nightingaleana propunha uma educação de enfermeiros com base em postulados de comodidade, necessidade, saúde, prevenção e manejo do ambiente, separada e orientada diferentemente da medicina (Huarcaya, 2003). Numa tentativa de listagem, Geovanini et al. (2002) afirmaram que as primeiras escolas de enfermagem no Brasil foram: Alfredo Pinto, Escola da Cruz Vermelha do Rio de Janeiro, Escola Anna Nery, Escola Carlos Chagas, Escola Luisa de Marillac, Escola Paulista de Enfermagem e Escola de Enfermagem da USP.

Três anos mais tarde (1926), a primeira escola oficial de enfermagem no Brasil (EEDNSP) receberia o nome de Escola de Enfermeiras Dona Anna Néry (pioneira brasileira da enfermagem). Nesse período ainda não existia universidade oficialmente reconhecida no Brasil, o que viria acontecer somente depois da criação do Estatuto das Universidades Brasileiras, com Francisco Campos (1931). Somente por meio do Decreto 21.321 de 18/06/1946 (Brasil, 1964), no início da retomada da democratização no Brasil pela queda de Vargas, é que esta escola se integrou à Universidade do Brasil.

A grande reforma do ensino de enfermagem ocorreu em 1949, pela lei $n^{\circ} 775$ de 06 de Agosto de 1949 (Brasil, 1974), que padronizou o ensino de enfermagem. E do Decreto $n^{\circ} 27.426$ de 14 de Novembro de 1949, o qual estabeleceu o currículo para a formação do enfermeiro (Brasil, 1949).

Com a promulgação da LDBEN 4.024/61 (Brasil, 1961), levando em consideração as transformações econômicas e necessidade de mão de obra com mais fluidez, cujo ideário era encampado, inclusive, por alguns intelectuais na área da saúde, duas emendas foram incorporadas no artigo 47, que tratava da criação do ensino técnico da enfermagem em grau Médio, e nos artigos 90 e 91, que incluíam a assistência da enfermagem ao escolar. Esse encaminhamento resultou no Parecer 171/1966 (Brasil, 1966), que regulamentava os cursos técnicos de enfermagem no Brasil, e o reconhecimento, propriamente dito, da enfermagem como curso Superior (Araújo, Silva, 2007).

O currículo do curso de enfermagem numa perspectiva instrumental - cujo centro era o manejo de técnicas - a partir da Lei 5.540 de 1968 (Brasil, 1968), é ainda mais enfatizado, sobretudo, por conta da influência norte-americana, naturalizada, inclusive, por meio de acordos bilaterais, com uma iniciativa diferente - a inclusão das disciplinas sociologia e psicologia, numa orientação funcionalista e behaviorista. Nesse momento histórico em que vivia o Brasil (ditadura militar), a inclusão das disciplinas acima, conforme o Parecer CFE 163/72 (Brasil, 1972), pode ser considerado um avanço, tendo em vista a ênfase de especialização do curso.

No final da década de 1960, a despeito de os estudos teóricos da enfermeira Wanda de Aguiar Horta apontarem para a necessidade do registro no planejamento da assistência (Carrijo, 2007), para a compreensão e melhor intervenção do enfermeiro em seu cotidiano, as práticas dos docentes universitários ainda eram centralizadas no modelo mecanicista de formação e instrumentalização dos futuros profissionais. Se havia, de um lado, uma projeção para mudança de planificação instrumental da formação, por outro, os parâmetros e finalidades tecnicistas no processo ensino-aprendizagem na universidade permaneciam inalteráveis. Esse quadro apresentou o mesmo arranjo nas legislações oficiais nacionais e subnacionais, até mesmo ante a LDBEN 9394/96 (Brasil, 1996), que garantia a formação de 
distintos perfis profissionais no Ensino Superior, considerando o mundo do trabalho e suas solicitações como ponto de partida.

Em 2001, foi homologado o parecer CNE/CES n 1133/2001 (Brasil, 2001b), que definiu as Diretrizes Curriculares Nacionais dos Cursos de Graduação, e a Resolução n 03/2001 (Brasil, 2001a), instituiu as diretrizes específicas para o ensino de graduação em Enfermagem (Machado, 2007), mas, ainda assim, o processo interdisciplinar de formação não se consubstanciou como questão resolvida.

Do ponto de vista da lógica capitalista, tanto a enfermagem quanto qualquer outro curso universitário só encontram respaldo quando articulados ao "mercado de trabalho", e não necessariamente ao "mundo do trabalho". Eis o explícito legal e a sua operacionalização diferenciada implícita, característica de uma sociedade dualista, cuja leitura o professor de Ensino Superior, nos cursos de enfermagem, necessita problematizar, ressignificando a sua ação formativa do profissional cidadão verdadeiramente para o mundo do trabalho em todas as suas múltiplas determinações.

\section{Perspectiva profissional e social da enfermagem: uma problematização da identidade docente}

A enfermagem, em sua origem, está relacionada com a missão da igreja ou pessoas leigas que tinham desenvolvido um espírito missionário, cuja base centrava-se na caridade e misericórdia (Rodrigues, 2000). Daí a proliferação das Casas de Misericórdia (do coração que se inclina aos pobres), a partir do século XV, lideradas por Ordens religiosas distintas e a modelação do conceito de enfermagem como a arte e a ciência do cuidar, característicos da missão do cristianismo, sobretudo no que diz respeito aos desfavorecidos econômica e socialmente. Com o passar dos séculos e modificações derivadas das novas formas de produção, a enfermagem como área de conhecimento solicita modificações quanto às políticas públicas sociais.

A enfermagem como profissão surgiu com Florence Nightingale (1820-1910), reconhecida como precursora da Enfermagem Moderna (Carrijo, 2007). No decorrer da história, Florence destacou a peculiaridade do trabalho em enfermagem quando o distingue das tarefas domésticas e reconhece o seu cunho científico, conferindo-Ihe status específico e autoridade como área de conhecimento, despontando a enfermagem profissional (Abrão, 2006) como de formação específica. Entretanto, como destacado anteriormente, a enfermagem como profissão possui enredo diferenciado em sua trajetória, pois está intimamente ligada ao servir social. A sua relação com a sociedade é permeada pelos conceitos que se estabeleceram na sua trajetória histórica e que influenciam, até hoje, a concepção do que é, e qual o seu significado enquanto profissão da saúde (Padilha, Borenstein, 2006).

A enfermagem como área de conhecimento profissional está articulada ao contexto social em todo o mundo. Sua prática está profundamente interligada com os fatos sociais, culturais, históricos e políticos, com os quais os seres humanos vivem e se relacionam (Huarcaya, 2003). Entretanto, várias são as dimensões de sua compreensão, enquanto profissão e enquanto prática social ao longo do processo histórico (Abrão, 2006).

Para Paixão (1969), existem três elementos principais para se compreender tais dimensões, os quais constituem a profissão do enfermeiro, a saber: o espírito de serviço (ou ideal), habilidade (arte) e ciência. Porém, destaca que o mais importante é o espírito de serviço, por ser uma inclinação natural no homem, ser social por excelência. Para Shinyashiki (2006), as pessoas que assumem o papel de enfermeiro não somente assimilam novos conhecimentos e aprendem novas habilidades, mas imergem em uma nova cultura com expectativas de valores e normas e, acrescentamos, na possibilidade de recriação e ampliação do mundo e seus arranjos contextuais.

Kemmer e Silva (2007) enfatizam que a enfermagem como profissão tem caminhado para a formação de um corpo próprio de conhecimentos científicos, buscando, por meio de estudos e pesquisas, a sua definição como ciência. Entretanto, Pai, Schrank e Pedro (2006) denunciam que o trabalho de enfermagem no Brasil acontece, muitas vezes, sob condições precárias de recursos humanos e materiais, baixos salários, ambientes insalubres, dividido por tarefas e com extensas horas de trabalho, e que, na maioria das vezes, não oferece local apropriado ao descanso. 
Huarcaya (2003) destaca que o sentido da identidade profissional não consiste em atingir um modelo ideal de enfermeiro, mas de entender sua história, situar-se no contexto e olhar em perspectiva. Significa, também, a reconstrução da autoimagem e da autoestima, a procura de satisfações profissionais dentro do trabalho realizado.

Perante esse amplo campo de significações e ressignificações profissionais e acadêmicas, coloca-se o docente do curso de enfermagem, que pode orientar-se por uma ação interventiva centrada na formação instrumental do cuidar humano, como sinalizam os autores tradicionais da área, ou, sem perder o foco, ampliar as possibilidades de o futuro profissional enxergar-se num contexto social mais amplo, isto é, o de estudioso permanente da área.

Nessa diretriz, as interlocuções com as questões macrossociais podem contribuir para a elaboração de uma identidade profissional comprometida e coerente com o projeto de emancipação social, assim os profissionais não são reduzidos a "fazedores" parcelizados de tarefas, mas construtores de conhecimento em serviço ou em espaço permanente de formação continuada, o que os impulsiona a refletir sobre a formação docente para o curso de enfermagem com maior profundidade.

\section{A formação docente para o curso de enfermagem e a trilogia ensino-pesquisa e extensão: aspectos didático-pedagógicos}

Cumpre ao docente universitário a ampliação de sua visão acerca do conhecimento, dos saberes pedagógicos necessários ao desenvolvimento de sua atribuição, das possibilidades de sua própria formação profissional continuada e acerca dos princípios que prezam pela dignidade e eticidade (dentre outros) humanas: sua, dos seus alunos, de sua comunidade e do homem em todo o universo de sua produção. Esta ampliação necessária se caracteriza pelo "desarmar-se" acerca de concepções acabadas sobre o conhecimento historicamente produzido, isto é, cabe ao educador assumir que, por meio dos tempos, o conhecimento do homem se amplia e se refaz, se corrige e possibilita novas leituras de um mundo que precisa ser redescoberto a cada encontro e a cada achado científico que se elabora, e que, por sua vez, deve ser estudado e entendido à luz de teias relacionais intrínseca e extrinsecamente, conforme as possíveis visões de totalidades científicas e humanas que se apresentam disponíveis e em processo de construção.

Para a enfermagem, a formação do docente segue os mesmos referenciais dos demais cursos superiores no Brasil, isto é, considerando a sua formação em nível de graduação, especializações e cursos Strictu Sensu (Mestrado e Doutorado). A partir da última LDBEN 9394/96 (Brasil 1996), a ênfase deve se dar na contratação de professores com nível Strictu Sensu em, pelo menos, 1/3, considerando os demais níveis (graduação e especialização) a partir do mérito de cada candidato e exigências institucionais dentre outros.

O perfil do profissional a ser formado para a área da enfermagem, consequentemente, como vimos no artigo 43 da LDBEN 9394/96, prima pela formação inicial e continuada desse profissional, o que requereria intervenções diferenciadas cujos referenciais possam exprimir a leitura do real. Entretanto, observamos que historicamente os referenciais epistemológicos para a enfermagem orientam grande parte dos futuros profissionais, para o grupo dos executores, reduzindo de forma utilitária "o cuidar" ao sentido de abnegação de sua tradição.

Segundo Huarcaya (2003), o modelo nightingaleano adotou muito do espírito religioso que norteou as práticas do cuidado como atividades específicas de enfermagem. A escola de Florence serviu de modelo para a enfermagem em vários países do mundo. O modelo vocacional era um modelo internalizado e legitimado pelas alunas durante o processo de formação. Florence Nightingale destacava que a Enfermagem era um chamado, uma vocação em que as enfermeiras poderiam mostrar sua docilidade, sua "vocação de serviço", relacionadas com a obediência religiosa.

A filosofia de vida de Florence permeava todo o currículo de sua escola. Ela acreditava que a saúde deveria estar presente tanto na alma como no corpo. Seu currículo não tinha um conjunto de metas a ser atingido, sua ênfase centrava-se nos talentos e habilidades das estudantes que compartilhavam a missão do enfermeiro e que deveriam ser desabrochados. De acordo Pinhel (2006), o treinamento era 
uma forma de fazer com que a aluna usasse seus recursos intelectuais inatos, logo, a escola deveria ensinar à enfermeira sua função de ajudar o paciente a viver.

Portanto, a enfermagem era entendida como uma arte que requeria treinamento organizado, prático e científico; a enfermeira deveria ser uma pessoa capacitada a servir a medicina, a cirurgia e a higiene, e não a servir aos profissionais dessas áreas. Florence defendia que a enfermagem era corolário necessário desses campos e que, para o bem-estar dos pacientes, a enfermeira deveria saber adaptar suas habilidades ao trabalho da equipe e, para isso deveria obedecer, de forma inteligente, as solicitações do campo. Conforme Pimenta e Anastasiou (2002), ainda que os docentes universitários possuam experiência expressiva na área de atuação, há um despreparo e um desconhecimento científico do que seja o processo de ensino-aprendizagem.

O o docente universitário deve ampliar permanentemente a sua compreensão do próprio conhecimento, seu processo evolutivo e as maneiras possíveis de comunicá-lo. Dessa maneira, desperta em si e nos alunos a condição de protagonistas na descoberta das manifestações do conhecimento em sua vivência e interpretação; assim, o conhecimento não deve ser entendido com viés determinista, mas como um objeto em construção, solicitando a sensibilização do educador e do educando, em comunhão, para "aprender a aprender", para considerar possibilidades, para reunir hipóteses e para entender que o homem mobiliza a história e mobiliza-se com a história num processo de vir-a-ser, considerando e reconsiderando seus encaminhamentos à luz da reflexão de seus desafios, como objeto processual e dinâmico e, por isso mesmo, sujeito a possíveis transformações na medida em que constrói os seus saberes.

Nesse olhar, para Reibntz e Prado (2006), tornar-se professor na área de enfermagem requer mais do que ser bom profissional, isto é, são necessárias competências especificas que vão além das competências requeridas para um bom enfermeiro. E, vale lembrar, que provocar a construção da sensibilização para as mesmas é um dos desafios do professor, ou seja, além de ser capaz de desdobrar e dominar o campo do conhecimento deve educar o olhar contextual (seu e do estudante) sobre a historicidade vivenciada e os respectivos condicionantes sociais, o que certamente contribuirá com a transformação tanto do processo educacional, como dos indivíduos em seus posicionamentos.

Todavia, toda transformação gera um conflito, uma vez que provoca rupturas de conceitos, hábitos, preconceitos e comportamentos, dentre outros. Pode-se dizer que uma pedagogia transformadora é sempre uma pedagogia do conflito (Padovani, 2007). Nessa diretriz, Freire (1996) acrescenta que a formação de professores deve estar inserida numa reflexão sobre a prática educativa em favor da autonomia dos indivíduos, uma vez que os homens se educam por meio de intercâmbios, socializações e da construção da história do conhecimento humano.

As bases epistemológicas do curso de enfermagem, as intervenções didático-pedagógicas e a leitura transversalizada do professor, a partir desse conjunto identificado, reúnem parte dos elementos para o exercício significativo de sua intervenção. Parte, porque esse primeiro passo necessita estar articulado ao desenvolvimento discente e sua compreensão do mundo concreto, das contribuições da área que escolheu e das inferências provocadas pela dialogicidade recorrente da ação-reflexão-ação. O trabalho transversal do docente da área de enfermagem não se reduz puramente ao campo didático-pedagógico, mas não prescinde do mesmo para formação significativa do profissional, dado que pressupõe pontos de encontro das distintas áreas do saber que primam pelo conhecimento do objeto em sua totalidade. Assim, os conteúdos são atravessados como integrantes da totalidade e que encontram sentido com outras interconexões, pois o mundo mudou, as pessoas mudaram, e a simples constatação da velocidade em que ocorrem transformações em nossa vida cotidiana já nos mostra que estamos diante de uma nova sociedade, uma outra realidade que nos envolve e nos desafia (Lima, 2008).

Nesse sentido, Antunes (2002) reforça a necessidade de capacitação permanente do docente como profissional consciente da responsabilidade sobre sua atuação, que precisa adquirir melhor conhecimento de si mesmo, no que é, no que faz, no que pensa e no que diz, e, ao mesmo tempo, sobre o outro, portanto, numa relação si-outro num processo de ressignificação dos saberes e fazeres. Ebisui (2004), por meio de pesquisa realizada entre professores que ministram aulas no curso de enfermagem, concluiu que os próprios profissionais caracterizam como frágil uma intervenção docente 
que não ressignifique o rol de conhecimentos específicos de sua área; logo, a responsabilidade do formador nunca pode perder de vista a dimensão crítica, criativa, inovadora, ética, facilitadora e, acrescentamos, problematizadora do processo ensino-aprendizagem.

Em relação ao papel do professor, por meio do olhar freireano, inferimos que a tomada de consciência para uma prática pedagógica ressignificada na/e pela convivência é um exercício de aprendizagem que aprimora o reconhecimento de que os conhecimentos, os valores, os sentidos das ações docentes são construídos por múltiplas vozes, que solicitam encontros dialéticos permanentes, mas que, em si, estão sempre em estado de "novidade de encaminhamentos e propósitos", não pela inediticidade de temáticas da escola e seu entorno, mas pelo acuramento do olhar sobre os fundamentos, consequências e implicações que tais objetos demandam frente a interesses identificados que inquietam os interlocutores por seu ocultamento; dessa maneira, a prática pedagógica ressignificada na convivência possibilita uma outra forma de aprendizagem para os alunos, para o professor e para toda a comunidade escolar.

O espaço de convivência não é o espaço onde os conflitos não existem, muito pelo contrário, é também o espaço onde se possibilita a exposição dos conflitos, mas longe de se constituir um muro de lamentações, caracteriza-se como uma "ponte" onde ninguém poderá atravessar no lugar dos interlocutores, porque a travessia, sendo personalizada, é um caminho de todos; assim, as resoluções dos conflitos são encaminhadas, são pensadas, são discutidas a partir da evocação das inquietações dos sujeitos. Sabe-se que as respostas podem até não serem consensuais, respeitada a diversidade das individualidades, mas podem alcançar uma dimensão democrática significativa em relação à unidade (uno) dos objetivos que todos compartilham, mesmo que de ponto de vista diferenciado; assim, mudam os sujeitos, e a prática pedagógica será orientada por uma autoridade legitimada em múltiplas leituras, onde todos, ao mesmo tempo, são atores e protagonistas da vida real da escola (Lima, 2010).

Dessa maneira, a pesquisa como parte inerente ao trabalho do professor universitário para o curso de enfermagem será ressignificada, porque orientada por uma finalidade profissional e social comprometida com as devolutivas institucionais e populacionais. O sentido da pesquisa norteada por uma dimensão transversalizada possibilita as percepções e dimensões da própria carreira: para o professor, o despertar e aprofundamento na construção do objeto; para o aluno em interação recorrente, a aprendizagem e produção do conhecimento ressignificado, e, para ambos, o desvelamento do mundo e do homem.

As práticas de extensão, por sua vez, articuladas às perspectivas destacadas, têm como objetivo a socialização e a disponibilização do acesso às contribuições científicas e tecnológicas, não excluindo quaisquer pessoas num processo contínuo de universalização do conhecimento. As grandes preocupações de países desenvolvidos, entretanto, são constituídas por outra lógica: formar um exército consumidor compatível, tanto na academia quanto numa dimensão social mais ampla. O âmbito de compreensão ressignificado pelo professor de Ensino Superior do curso de enfermagem o impelirá a posicionar-se com intervenções sociopolíticas ressignificadas, isso não significa que somente tangenciará o aporte instrumental da profissão e papel específico da área, ao contrário, poderá expandir de forma transversal o alcance do processo ensino-aprendizagem e construir um espaço universitário problematizador.

Nesse contexto, a educação universitária assume a tarefa social de despertar, no homem, a consciência de si e do outro no mundo, contribuindo, de forma relevante, para o seu crescimento formativo e informativo, favorecendo o exercício ativo em todos os processos de sua história (e implicações advindas desses). Dessa forma, poderá desfazer as tramas reducionistas dessa realidade histórica (que é, sobretudo, vivida), considerando o universo relacional que possui essencialmente um caráter multidimensional, cuja finalidade maior é a de elevar o homem à categoria de sujeito de sua construção histórica, mediatizada pela compreensão, interpretação e crítica de sua realidade. Lima (2010) observa que a valoração do homem como ser que se autoproduz, transforma e se transforma no desvelamento do mundo e dos demais homens, adquire um caráter libertador; nas palavras de Paulo Freire (1980, p.34), a sua "a vocação ontológica do homem - vocação de ser sujeito - e as condições em que ele vive: em tal lugar exato, em tal momento, em tal contexto". 


\section{Considerações finais}

Nota-se que, à medida que o docente tem clareza em relação aos seus projetos e leitura dos condicionantes sócio-históricos, há uma relevante contribuição para sua formação profissional consciente e compromissada, assumindo um papel significativo de colaboração e transformação do aprenderensinar no ciclo ação-reflexão-ação. Assim, é necessário que o profissional de enfermagem, em seu processo de formação inicial, continuada ou de intervenção pedagógica na práxis, tenha consciência do amplo espectro da profissão, não como dádiva do sobrenatural, mas como processo em construção.

Tal perspectiva contribui para se compreender a intervenção pedagógica na enfermagem como uma profissão para além do instrumentalismo. Nesse caso, o professor, como pesquisador de seu próprio campo, é responsável por contribuir com a formação de profissionais competentes e conscientes da dimensão de sua intervenção no contexto social e, acima de tudo, que entendam que o educar está inserido em todos os momentos da enfermagem, pois, se ensina e aprende no exercício da construção do conhecimento.

Organizar a prática pedagógica sob o prisma da reflexão-na-ação não é, e jamais foi, sinônimo de permissividade ou de reducionismo, mas, ao contrário, é aperfeiçoá-la, tornando-a dinâmica, criativa e agradável; nesse caso, o professor é ator e autor social, que deve primar por sua formação e atualização permanente, ao mesmo tempo em que busca seu aperfeiçoamento e superação em cada olhar, tendo o aluno como um interlocutor ativo do processo ensino-aprendizagem e todos os outros professores como tessitura da mesma rede, construída e compartilhada por atores sociais históricos, dentre os quais o professor de Ensino Superior na enfermagem pode contribuir significativamente.

A visão de conjunto toma a totalidade como fio condutor, a fim de acompanhar todo um processo que se torna revolucionário no afrontamento ao reducionismo e à fragmentação, rumando-se à proposição de delineamentos coerentes e consistentes com o real social e educacional - revisão essa que não admite mais padronizações dos próprios saberes e fazeres da escola nem de verdades e visão de homem determinadas por conta de manutenção de vontades particulares daí a importância de uma educação compreensiva balizada em valores sociais, antropológicos, políticos, filosóficos, culturais e, sobretudo, valores humanos universalizados.

Esse norteamento é o veículo que vai situar a universidade, destacando o curso de enfermagem como elemento de transformação social; assim, importa que o professor, em seu processo de formação continuada, conheça e inclua o comprometimento pela educação: a totalidade da leitura do contexto pelo qual atravessa o mundo, o planeta, o país, o Estado, o município, o bairro, a comunidade extraescolar, a escola e a universidade, como objetos indissociáveis do conhecimento no exercício de sua prática docente.

Consideradas as múltiplas determinações sócio-históricas, é necessário ressignificar a formação do professor do ensino superior em enfermagem, instrumentalizando-o com saberes e fazeres críticoreflexivos, imprescindíveis à formação de profissionais-cidadãos. Esta não se esgota na área das ciências naturais, uma vez que seu objeto tem início e recorrência no humano: assim, um não nega o outro e, consequentemente, a transversalidade recorrente aprimora e fornece elementos necessários para seu crescimento e aperfeiçoamento contínuos.

Ressaltamos que não há pretensão de respondermos a todos os questionamentos referentes ao tema tratado. Desejamos, sim, oferecer elementos para trazer à luz esse campo de discussão e indicar perspectivas de pesquisa para futuros trabalhos. A formação do professor de Ensino Superior no Brasil necessita ultrapassar a lógica de uma ciência determinista que, não raras vezes, exclui o homem de sua humanização, isto é, valida somente aspectos pontuais, deixando à margem o que julga descartável, daí tornar tangencial, no currículo do enfermeiro, as solicitações das ciências humanas. Cremos que o teor comunicacional e interdisciplinar entre as áreas de conhecimento enriquece a formação profissional de qualquer profissional e, particularmente, a visão do docente universitário, cujo trabalho contempla a formação de inúmeros atores sociais que, por sua vez, poderão compartilhar ou aprofundar tais solicitações como um recorrente vir a ser, sem esquivar-se dos fazeres necessários à sua profissão — eis o porquê da centralidade da formação profissional e social do professor de enfermagem no crivo açãoreflexão-ação. 


\section{Colaboradores}

Os autores trabalharam juntos em todas as etapas de produção do manuscrito.

\section{Referências}

ABRÃO, F.M.S. Primórdios da enfermagem profissional na cidade de Recife/ Pernambuco: raízes de pré-institucionalização da formação do campus organizacional (1922-1938). 2006. Tese (Doutorado) - Escola de Enfermagem de Ribeirão Preto, Universidade São Paulo, Ribeirão Preto. 2006.

ANTUNES, M.N.V. A formação continuada do professor universitário de Enfermagem: discutindo sua contribuição com as mudanças no ensino de enfermagem. 2002. Dissertação (Mestrado) - Faculdade de Educação, Universidade Estadual de Campinas, 2002.

ARAUJO, D.V.; SILVA, C.C. Historicidade institucional do ensino de enfermagem na Paraíba: uma contribuição para o estudo. Cogitare Enferm., v.12, n.1, p.14-9, 2007.

BRASIL. Decreto n.791, de 27 de setembro de 1890. Crêa no Hospício Nacional de Alienados uma escola profissional de enfermeiros e enfermeiras. Rio de Janeiro Imprensa Nacional, 1890. Disponível em: <http://www6.senado.gov.br/legislacao/ ListaTextolntegral.action?id=53774>. Acesso em: 13 abr. 2010.

Ministério da Educação. Conselho Nacional de Educação. Câmara de Educação Superior. Resolução CNE/CES n. 3, de 07 de novembro de 2001. Institui Diretrizes Curriculares Nacionais do curso de graduação em Enfermagem. Diário Oficial da União, Brasília, 9 nov. 2001a. Seção 1, p.37.

.Ministério da Educação e Cultura. Parecer CNE/CES n.1133/2001. Aprovado $\overline{\text { em } 7 \text { de }}$ agosto de 2001. Diretrizes Curriculares Nacionais dos cursos de Enfermagem, Medicina e Nutrição. Diário Oficial da União, Brasília, 03 out, 2001b.

Ministério da Educação e Cultura. Lei n. 9.394, de 20 de dezembro de 1996. Estabelece as Diretrizes e Bases da Educação Nacional. Diário Oficial da União, Brasília, 23 dez. 1996. p.27.833-27.841.

Lei n.775, de 6 de agosto de 1949. Dispõe sobre o ensino de enfermagem no País e dá outras providências. Rio de Janeiro: Ministério de Serviços de Saúde Pública, 1974. v.1, p.154-7.

Conselho Federal de Educação. Parecer 163/72. Currículo mínimo para os cursos de graduação em enfermagem e obstétrica. Diário Oficial da União, Brasília, 25 fev. 1972.

Lei n.5.540, de 28 de novembro de 1968. Fixa normas de organização e funcionamento do ensino superior e sua articulação com a escola média, e dá outras providências. Diário Oficial da União, Brasília, 29 nov. 1968. Seção 1, p.10369.

Parecer n.171 de 22 de dezembro de 1966. Regulamenta os cursos técnicos e superior na área de enfermagem Diário Oficial da União, Brasília, 22 dez. 1966, Seção 2, p. 2 .

Decreto n.21.321, de 1946. Aprova o Estatuto da Universidade no Brasil. Rio de Janeiro: Imprensa Nacional, 1964.

. Ministério da Educação e Cultura. Lei n.4.024, de 20 de dezembro de 1961.

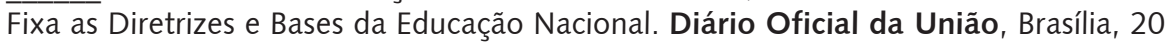
dez. 1961. 
BRASIL. Decreto n.27.426, de 14 de Novembro de 1949. Aprova o regulamento básico para os cursos de enfermagem e de auxiliar de enfermagem. Diário Oficial da União, Rio de Janeiro, 19 dez. 1949. Seção 1, p.17517.

Decreto n.15.799, de 10 de novembro de 1922. In: Collecção das Leis da República dos Estados Unidos do Brasil de 1922. Rio de Janeiro: Imprensa Nacional, 1923. v.4.

Decreto n.3.987, de 2 de janeiro de 1920. Cria o Departamento Nacional de Saúde Pública. In: Collecção das Leis da República dos Estados Unidos do Brasil de 1920. Rio de Janeiro: Imprensa Nacional, 1921. v.1.

CARRIJO, A.R. Registros de uma prática: anotações de enfermagem na memória de enfermeiras da primeira escola nightingaleana no Brasil (1959-1970). 2007.

Dissertação (Mestrado) - Escola de Enfermagem, Universidade de São Paulo, São Paulo. 2007.

EBISUI, C.T.N. A identidade profissional do enfermeiro professor do ensino técnico de enfermagem. 2004. Dissertação (Mestrado) - Escola de Enfermagem de Ribeirão Preto, Universidade São Paulo, Ribeirão Preto. 2004.

FREIRE, P. Conscientização, teoria e prática da libertação: uma introdução ao pensamento de Paulo Freire. 3.ed. São Paulo: Moraes, 1980.

Pedagogia da autonomia: saberes necessários à prática educativa. 31.ed. São Paulo: Paz e Terra, 1996.

GEOVANINI, T. et al. História da Enfermagem: versões e Interpretações. 2.ed. Rio de Janeiro: Revinter, 2002.

GOERGEN, P.L. A avaliação universitária na perspectiva da pós-modernidade. Avaliação, v.2, n.3, p.53-65, 1997.

HUARCAYA, S.S.L. Representações sociais de estudantes de enfermagem sobre a identidade profissional da enfermeira em Trujillo - Peru. 2003. Tese (Doutorado) Escola de Enfermagem Anna Nery, Universidade Federal do Rio de Janeiro, Rio de Janeiro. 2003.

KEMMER, L.F.; SILVA, M.J.P. Nurses' visibility according to the perceptions of the communication professionals. Rev. Latino-Am. Enferm., v.15, n.1, p.191-8, 2007.

LIMA, P.G. Saberes pedagógicos da educação contemporânea. Engenheiro Coelho/SP: Centro Universitário Adventista de São Paulo, 2007.

Transversalidade e docência universitária: por uma recorrência dialética do ensinar e aprender. Educação, v.33, n.3, p.457-68, 2008.

Universidade e educação básica no Brasil: a atualidade do pensamento de Paulo Freire. Dourados: Editora da UFGD, 2010.

MACHADO, V.B. Estudo sobre a formação de competências de alunos de graduação em enfermagem na vivência (simulada) em uma Clínica de Enfermagem. 2007. Tese (Doutorado) - Escola de Enfermagem de Ribeirão Preto, Universidade São Paulo, Ribeirão Preto. 2007.

OGUISSO, T.; FREITAS, G.F. Nursing history: reflections on teaching and research at undergraduate level. Rev. Latino-Am. Enferm., v.15, n.1, p.174-6, 2007.

PADILHA, M.I.C.S. et al. A produção da pesquisa histórica vinculada aos programas de pós-graduação no Brasil, 1972 a 2004. Texto Contexto Enferm., v.16, n.4, p.671-9, 2007.

PADILHA, M.I.C.S.; BORENSTEIN, M.S. História da Enfermagem e interdisciplinaridade. Escola Anna Nery. Rev. Enferm., v.10, n.3, p.325-38, 2006. 
PADOVANI, O. A prática pedagógica na educação profissional técnica de nível médio em Enfermagem: estudo em uma escola privada do interior paulista. 2007. Dissertação (Mestrado) - Escola de Enfermagem de Ribeirão Preto, Universidade São Paulo, Ribeirão Preto. 2007.

PAI, D.D.; SCHRANK, G.; PEDRO, E.N.R. O enfermeiro como ser sócio-político: refletindo a visibilidade da profissão do cuidado. Acta Paulista Enferm., v.19, n.1, p.82-7, 2006.

PAIXÃO, W. Historia da enfermagem. 4.ed. Rio de Janeiro: Bruno Buccini, 1969.

PIMENTA, S.G.; ANASTASIOU, L.G.C. Docência no ensino superior. São Paulo: Cortez, 2002.

PINHEL, I. O desenvolvimento de competência para a docência segundo a vivência de docentes de um curso de graduação em enfermagem. 2006. Tese (Doutorado) Escola de Enfermagem na Universidade de São Paulo, São Paulo. 2006.

PIRES, M.R.G.M. Pela reconstrução dos mitos da enfermagem a partir da qualidade emancipatória do cuidado. Rev. Esc. Enferm. USP, v.41, n.4, p.717-23, 2007.

REIBNITZ, K.S.; PRADO, M.L. Inovação e educação em enfermagem. Florianópolis: Cidade Futura, 2006.

RODRIGUES, R.M. Teoria e prática assistencial na enfermagem: o ensino e o mercado de trabalho. 2000. Dissertação (Mestrado) - Escola de Enfermagem de Ribeirão Preto, Universidade São Paulo, Ribeirão Preto. 2000.

SHINYASHIKI, G.T. et al. Professional socialization: students becoming nurses. Rev. Latino-Am. Enferm., v.14, n.4, p.601-7, 2006.

LIMA, P.G.; SANTOS, P.L.F. Solicitudes profesionales y sociales del profesor universitario de enfermería en el Brasil. Interface - Comunic., Saude, Educ., v.15, n.39, p.1097-109, out./dez. 2011.

En ese trabajo analizamos las solicitudes profesionales y sociales del profesor universitario del curso de enfermería en Brasil frente a las exigencias, identidad y formación didáctico-histórica de su campo de conocimiento por medio de una revisión de literatura especializada. Las conclusiones apuntaron para una necesaria reflexión del área, rompiendo con la lógica meramente instrumental tanto del profesor cuanto del profesional a ser formado, a medida que el cribo acción-reflexión-acción ocupa la centralidad de la interacción de los saberes y haceres en una perspectiva humanizada.

Palabras clave: Enfermería. Docentes de enfermería. Formación didáctico-pedagógica. 